\title{
Speciality Grand Challenges in Organometallic Catalysis
}

\author{
Alceo Macchioni * \\ Department of Chemistry, Biology and Biotechnology and CIRCC, University of Perugia, Perugia, Italy
}

Keywords: homogeneous catalysis, supported catalysis, bio-organometallic catalysis, cluster catalysis, organometallic catalysis

The interaction between a metal center (M) and a molecular moiety (substrate) is the basis of most catalytic processes. The chemical environment surrounding $\mathrm{M}$ can equally be a set of suitable ligands (Coordination Catalysis) (Crabtree, 2014), a set of properly engineered/functionalized ligands anchored onto a solid support (Single-Site Surface Coordination Catalysis) (Copéret et al., 2016), a small cluster of metal atoms as well as a lattice of a material (Heterogeneous Catalysis) (Friend and $\mathrm{Xu}, 2017$ ), and an enzymatic framework (Biocatalysis) (Schwizer et al., 2018) (Figure 1).

If at least one of the $\mathrm{M}$-environment interactions involves an $\mathrm{M}-\mathrm{R}$ bond (where $\mathrm{R}=\mathrm{C}$ and $\mathrm{H}$ ), all types of catalysis listed above are by definition Organometallic Catalysis. Furthermore, even in the absence of a M-R bond in the starting molecule/material, the catalytic process may be still defined as of organometallic nature if a $\mathrm{M}-\mathrm{R}$ fragment forms in any step of the catalytic cycle. These simple considerations clearly indicate the generality and importance of organometallic catalysis. Relevant examples of organometallic catalysis, for each of category illustrated above, are very well known and reported in the textbooks (Drauz et al., 2012; Bochmann, 2014).

The success of organometallic catalysis may be ascribed to the capability of a metal to activate lowenergy reaction pathways along which the deformed substrate, stabilized through coordination at a properly designed $\mathrm{L}_{\mathrm{n}} \mathrm{M}$-fragment, is induced to react in a novel and original way. This explains why some reactions are exclusive of coordination/organometallic complexes. In this respect, a classical example is the reductive elimination, which is one of the fundamental steps of organometallic catalytic cycles (Hartwig, 1998; Chen et al., 2017; Chu and Nikonov, 2018; Wolczanski, 2018). It involves the release of $\mathrm{R}-\mathrm{X}$ from a $\left(\mathrm{L}_{\mathrm{n}} \mathrm{MXR}\right)$ complex, where oxidation state, coordination number and electron of the metal center are reduced by two units.

As a result of this propensity to activate a substrate by opening low-energy reaction pathways, the activity of organometallic catalysts can be so high that a $<10^{-6} \mathrm{M}$ active metal concentration is sufficient for carrying out the reaction efficiently: in these cases, catalyst separation and recovery from the products might even be avoided, as it occurs in some industrial polymerization processes (Stürzel et al., 2016). This notwithstanding, catalyst recovery is still necessary is many cases, and typically more easily achievable with heterogenous rather than molecular systems. For this reason, industrially relevant molecular catalysts are often heterogenized onto suitable supports, as mentioned above, leading to heterogeneous catalysts with similar (ideally the same) activity and selectivity to the molecular counterpart, but with the additional advantage of being easy to separate from the reaction environment and recycle (Schwarz et al., 1995; McNamara et al., 2002; Witzke et al., 2020).

Selectivity is another strong suit of organometallic catalysis, which can be achieved by tailoring the chemical environment of the active metal by proper selection/combination of ligands. As a matter of fact, chemical, regio-and stereo-selectivity approaching $100 \%$ have been obtained for many reactions of industrial relevance, even in non-enzymatic systems.

Importantly, the effectiveness of organometallic catalysts stems also from possible M-environment cooperativity. The latter may involve ligands, which may be redox active or bear a dandling functionality (a base, an acid, etc.), support, other metallic centers (both in 

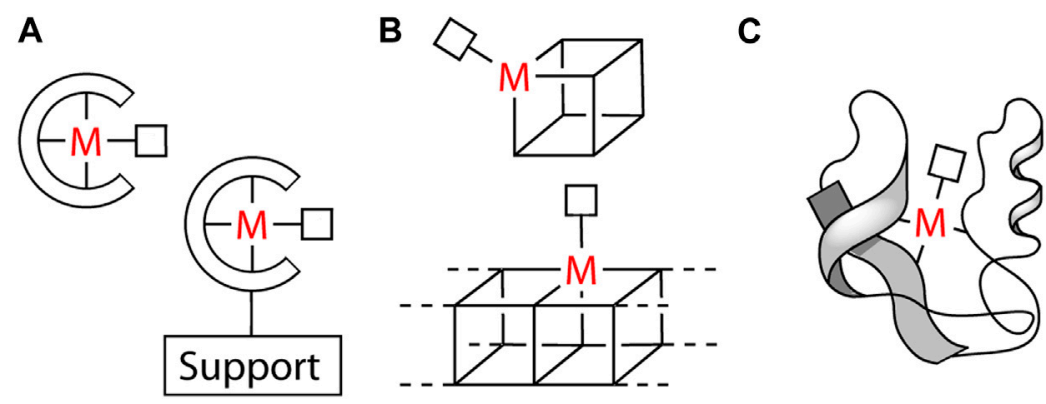

FIGURE 1 | (A) Coordination and Single-Site Surface Coordination Catalysis; (B) Cluster and Heterogeneous Catalysis; (C) Biocatalysis. The empty square linked to $\mathrm{M}$ represents a coordination vacancy.

molecular clusters and extended lattices) and even an enzymatic framework. Notable in the latter respect are the recent developments of artificial metalloenzymes, in which non-native activating metal ions is accommodated in a protein scaffold, to induce selectivity to catalytic process (Schwizer et al., 2018; Lombardi et al., 2019).

Despite the versatility of organometallic catalysis and its paramount success, many open challenges can be foreseen for the next decades. One that the scientific community is very aware of is the replacement of noble-metal organometallic catalysts with those based on earth-abundant analogues (Bolm, 2009; Chirik and Morris, 2015; Roger et al., 2017). This is not a simple task, due to the typical superior reactivity of the former systems. Traditionally, the best performances in most relevant catalytic processes have been obtained by using the Pt group metals (Albrecht and van Koten, 2001; Johansson Seechurn et al., 2012; Lyons and Sanford, 2010; Seechurn et al., 2012; Labinger and Jay, 2017; Roger et al., 2017). The substitution of a rare and expensive metal of the second and third transition rows (such as $\mathrm{Ru}, \mathrm{Rh}$, and Ir) is typically pursued by looking for an abundant and cheap metal of the first transition row belonging to the same triad (e.g., $\mathrm{Ru} \rightarrow \mathrm{Fe}, \mathrm{Rh} \rightarrow \mathrm{Co}, \mathrm{Pd} \rightarrow \mathrm{Ni}$ ) (Zhang et al., 2012; Smieja et al., 2013; Tasker et al., 2014; Wenger, 2019) or related by the diagonal relationship (e.g., $\mathrm{Ru} \rightarrow \mathrm{Mn}, \mathrm{Rh} \rightarrow \mathrm{Fe}$ ) (RaynerCanham, 2011; Zell and Langer, 2018). These replacements are often detrimental but not necessarily dramatic in terms of catalyst TurnOver Frequency (TOF), whereas they are surely more critical in terms of TurnOver Number (TON). Nevertheless, many research groups have obtained remarkable success in some important chemical transformations. For instance, hydroformylation is one of the largest scale processes of the chemical industry, traditionally relying on highly active $\mathrm{Rh}$ catalysts. Very recently (2020) Stanley and coworkers reported simple carbonyl Co complexes with performances comparable to those of noble metal systems; the key for high activity appears to be the cationic nature of the Co-complexes (Hood et al., 2020).

Another large-scale industrial field in which it would be important to develop non-noble metal catalysts concerns hydrogenation reactions (Filonenko et al., 2018). Among others, a recent interesting example has been reported by Beller and coworkers, who developed a Mn system for quinolones hydrogenation under mild conditions, consisting of a very simple and cheap Mn pentacarbonyl bromide complex (Papa et al., 2020). Other first row metals developed for $\mathrm{N}$-heteroarenes reduction include cobalt (Adam et al., 2017; Sahoo et al., 2018) and iron (Chakraborty et al., 2014). The transition from noble-to abundant-metal organometallic catalysts will surely continue to be one of the challenges for the scientific community for the years to come (Bullock, 2010).

For reactions where adequate non-noble metal catalysts are difficult to find, an alternative strategy could be trying to minimize the utilization of such precious elements, by maximizing their performance. In a way, it could be said that the "noble-metal atom economy" is pursued in those cases (Macchioni, 2019). This can be achieved, for instance, by anchoring a well-defined molecular catalyst onto a suitable support, thus facilitating the recovery and reuse of precious catalysts.

To this aim, the most commonly and successfully used supports include silica (Baffert et al., 2011; Wu et al., 2014), organic polymers (Arakawa et al., 2008; McNamara and Hicks, 2014) and metal oxides (Kaboudin et al., 2013). Furthermore, the modification of the surrounding environment of the supported metal complex can be a good opportunity to enhance the catalytic performance of the material (Maeda et al., 2020).

Alternatively, the minimization of precious M-atoms can be achieved by diluting them in a proper porous or layered material material based on earth-abundant elements, and having features that maximize $\mathrm{M}$-accessibility and performance. Among the class of materials with these features, metal organic frameworks (MOFs) are surely very attractive and are receiving a lot of attention (Yoon et al., 2012; Furukawa et al., 2013; Liu et al., 2014). For example they can be used as effective porous supports for inorganic catalysts (e.g., to prevent particle aggregation) (Yang et al., 2018) but also in combination with enzymes to reproduce cellular microenvironments (Chen et al., 2018). Importantly, they can also serve directly as catalysts (Zhang et al., 2018) often favoring cooperative effects (An et al., 2019). Also layered double hydroxides (LDHs) meet the requirement to be easily doped with active metals, ensuring a high percentage of active sites, especially after their exfoliation (Fan et al., 2014; Song and Hu, 2014; Cai et al., 2019; Laipan et al., 2019). An example has been recently reported in which microand nano-sized iridium-doped zinc-aluminum LDHs, 
containing as low as $1 \mathrm{wt} \%$ of noble metal, have been exploited in both chemical and electrochemical catalytic water oxidation, exhibiting excellent catalytic performances, comparable only to those of the most efficient molecular iridium catalysts, tested under similar reaction conditions (Fagiolari et al., 2020; Zaccaria et al., 2020). Many scientists are successfully pursuing both approaches to "noble-metal atom economy" that will surely be of great importance for the future.

Other challenges in which the community of catalytic organometallic chemists is likely to engage will be: 1) the development of heterogeneous stereoselective single-site catalysts (Dal Santo et al., 2012); 2) the application of organometallic catalysts in more sustainable, alternative media (Dixneuf and Soule, 2019); and 3) the development of biomimetic catalysts or structural or functional models of enzymatic catalysts (Zakzeski et al., 2010; Beller et al., 2017). These fundamental achievements are a necessary requirement for organometallic catalysis to play a significant role in the trans-disciplinary effort of the scientific community to drive the major societal transformations. In our century, characterized by the climate and energetic crises, this mostly means contributing to implement sustainable production processes based on innovative materials

\section{REFERENCES}

Adam, R., Cabrero-Antonino, J. R., Spannenberg, A., Junge, K., Jackstell, R., and Beller, M. (2017). A General and Highly Selective Cobalt-Catalyzed Hydrogenation of N-Heteroarenes under Mild Reaction Conditions. Angew. Chem. Int. Ed. 56 (12), 3216-3220. doi:10.1002/anie.201612290

Albrecht, M., and van Koten, G. (2001). Platinum Group Organometallics Based on "Pincer" Complexes: Sensors, Switches, and Catalysts. Angew. Chem. Int. Ed. 40 (20), 3750-3781. doi:10.1002/1521-3773(20011015)40:20<3750::aidanie3750>3.0.co;2-6

An, B., Li, Z., Song, Y., Zhang, J., Zeng, L., Wang, C., et al. (2019). Cooperative Copper Centres in a Metal-Organic Framework for Selective Conversion of CO2 to Ethanol. Nat. Catal. 2 (8), 709-717. doi:10.1038/s41929-019-0308-5

Arakawa, Y., Chiba, A., Haraguchi, N., and Itsuno, S. (2008). Asymmetric Transfer Hydrogenation of Aromatic Ketones in Water Using a Polymer-Supported Chiral Catalyst Containing a Hydrophilic Pendant Group. Adv. Synth. Catal. 350 (14-15), 2295-2304. doi:10.1002/adsc.200800362

Armaroli, N., and Balzani, V. (2007). The Future of Energy Supply: Challenges and Opportunities. Angew. Chem. Int. Ed. 46 (1-2), 52-66. doi:10.1002/anie. 200602373

Baffert, M., Maishal, T. K., Mathey, L., Copéret, C., and Thieuleux, C. (2011). Tailored Ruthenium-N-Heterocyclic Carbene Hybrid Catalytic Materials for the Hydrogenation of Carbon Dioxide in the Presence of Amine. Chem. Sus. Chem. 4 (12), 1762-1765. doi:10.1002/cssc.201100223

Beller, M., Centi, G., and Sun, L. (2017). Chemistry Future: Priorities and Opportunities from the Sustainability Perspective. Chem. Sus. Chem. 10 (1), 6-13. doi:10.1002/cssc.201601739

Bochmann, M. (2014). Organometallics and Catalysis: An Introduction. Oxford: Oxford University Press.

Bolm, C. (2009). A New Iron Age. Nat. Chem 1 (5), 420. doi:10.1038/nchem.315 Cai, Z., Bu, X., Wang, P., Ho, J. C., Yang, J., and Wang, X. (2019). Recent Advances in Layered Double Hydroxide Electrocatalysts for the Oxygen Evolution Reaction. J. Mater. Chem. A. 7 (10), 5069-5089. doi:10.1039/c8tal1273h

Chakraborty, S., Brennessel, W. W., and Jones, W. D. (2014). A Molecular Iron Catalyst for the Acceptorless Dehydrogenation and Hydrogenation of N-Heterocycles. J. Am. Chem. Soc. 136 (24), 8564-8567. doi:10.1021/ja504523b

Chen, P.-h., Billett, B. A., Tsukamoto, T., and Dong, G. (2017). "Cut and Sew" Transformations via Transition-Metal-Catalyzed Carbon-Carbon Bond Activation. ACS. Catal. 7 (2), 1340-1360. doi:10.1021/acscatal.6b03210
(Schneiderman and Hillmyer, 2017), energy sources (Armaroli and Balzani, 2007) and chemical feedstocks (Zakzeski et al., 2010).

In conclusion, it is reasonable to think that all the conditions are in place for the future of organometallic catalysis to be as successful as in the past decades. It is also foreseeable that an important key to such success will come from the marked interdisciplinary nature of organometallic catalysis.

\section{AUTHOR CONTRIBUTIONS}

The author confirms being the sole contributor of this work and has approved it for publication.

\section{FUNDING}

This work has been financially supported by University of Perugia and MIUR (AMIS "Dipartimenti di Eccellenza-2018/2022" program).

Chen, W.-H., Vázquez-González, M., Zoabi, A., Abu-Reziq, R., and Willner, I (2018). Biocatalytic Cascades Driven by Enzymes Encapsulated in MetalOrganic Framework Nanoparticles. Nat. Catal. 1 (9), 689-695. doi:10.1038/ s41929-018-0117-2

Chirik, P., and Morris, R. (2015). Getting Down to Earth: The Renaissance of Catalysis with Abundant Metals. Acc. Chem. Res. 48 (9), 2495. doi:10.1021/acs. accounts.5b00385

Chu, T., and Nikonov, G. I. (2018). Oxidative Addition and Reductive Elimination at Main-Group Element Centers. Chem. Rev. 118 (7), 3608-3680. doi:10.1021/ acs.chemrev.7b00572

Copéret, C., Comas-Vives, A., Conley, M. P., Estes, D. P., Fedorov, A., Mougel, V., et al. (2016). Surface Organometallic and Coordination Chemistry toward Single-Site Heterogeneous Catalysts: Strategies, Methods, Structures, and Activities. Chem. Rev. 116 (2), 323-421. doi:10.1021/acs.chemrev.5b00373

Crabtree, R. (2014). The Organometallic Chemistry of the Transition Metals. New Haven, CT: Sixth Edit. Wiley.

Dal Santo, V., Guidotti, M., Psaro, R., Marchese, L., Carniato, F., Bisio, C., et al. (2012). Rational Design of Single-Site Heterogeneous Catalysts: towards High Chemo-, Regio- and Stereoselectivity. Proc. R. Soc. A. 468 (2143), 1904-1926. doi:10.1098/rspa.2012.0056

Dixneuf, P. H., and Soule, J-F. (2019). Organometallics for Green Catalysis. Top. Organomet. Chem. 63, 1-295.

Fagiolari, L., Bini, M., Costantino, F., Gatto, G., Kropf, A. J., Marmottini, F., et al. (2020). Iridium-Doped Nanosized $\mathrm{Zn}-\mathrm{Al}$ Layered Double Hydroxides as Efficient Water Oxidation Catalysts. ACS Appl. Mater. Inter. 12 (29), 32736-32745. doi:10.1021/acsami.0c07925

Fan, G., Li, F., Evans, D. G., and Duan, X. (2014). Catalytic Applications of Layered Double Hydroxides: Recent Advances and Perspectives. Chem. Soc. Rev. 43 (20), 7040-7066. doi:10.1039/c4cs00160e

Filonenko, G. A., van Putten, R., Hensen, E. J. M., and Pidko, E. A. (2018). Catalytic (de)hydrogenation promoted by non-precious metals - Co, Fe and Mn: recent advances in an emerging field. Chem. Soc. Rev. 47 (4), 1459-1483. doi:10.1039/ c7cs00334j

Friend, C. M., and Xu, B. (2017). Heterogeneous Catalysis: A Central Science for a Sustainable Future. Acc. Chem. Res. 50 (3), 517-521. doi:10.1021/acs.accounts. $6 \mathrm{~b} 00510$

Furukawa, H., Cordova, K. E., O'Keeffe, M., and Yaghi, O. M. (2013). The Chemistry and Applications of Metal-Organic Frameworks. Science 341 (6149), 1230444. doi:10.1126/science.1230444 
Hartwig, J. F. (1998). Carbon-Heteroatom Bond-Forming Reductive Eliminations of Amines, Ethers, and Sulfides. Acc. Chem. Res. 31 (12), 852-860. doi:10.1021/ $\operatorname{ar} 970282 \mathrm{~g}$

Hood, D. M., Johnson, R. A., Carpenter, A. E., Younker, J. M., Vinyard, D. J., and Stanley, G. G. (2020). Highly Active Cationic Cobalt(II) Hydroformylation Catalysts. Science 367 (6477), 542-548. doi:10.1126/science.aaw7742

Johansson Seechurn, C. C., Kitching, M. O., Colacot, T. J., and Snieckus, V. (2012). Palladium-Catalyzed Cross-Coupling: A Historical Contextual Perspective to the 2010 Nobel Prize. Angew. Chem. Int. Ed. 51 (21), 5062-5085. doi:10.1002/ anie. 201107017

Kaboudin, B., Mostafalu, R., and Yokomatsu, T. (2013). Fe3O4 NanoparticleSupported $\mathrm{Cu}(\mathrm{ii})-\beta$-Cyclodextrin Complex as a Magnetically Recoverable and Reusable Catalyst for the Synthesis of Symmetrical Biaryls and 1,2,3-triazoles from Aryl Boronic Acids. Green. Chem. 15 (8), 2266-2274. doi:10.1039/ c3gc40753e

Drauz, K., Gröger, H., and May, O. (Editors) (2012). in. Enzyme Catalysis in Organic Synthesis. 3rd ed. (Weinheim, Germany: Wiley VCH).

Labinger, J. A., and Jay, A. (2017). Platinum-Catalyzed C-H Functionalization. Chem. Rev. 117 (13), 8483-8496. doi:10.1021/acs.chemrev.6b00583

Laipan, M., Yu, J., Zhu, R., Zhu, J., Smith, A. T., He, H., et al. (2019). Functionalized Layered Double Hydroxides for Innovative Applications. Mater. Horizons 7, 715-745. doi:10.1039/C9MH01494B

Liu, J., Chen, L., Cui, H., Zhang, J., Zhang, L., and Su, C.-Y. (2014). Applications of Metal-Organic Frameworks in Heterogeneous Supramolecular Catalysis. Chem. Soc. Rev. 43 (16), 6011-6061. doi:10.1039/c4cs00094c

Lombardi, A., Pirro, F., Maglio, O., Chino, M., and DeGrado, W. F. (2019). De Novo Design of Four-Helix Bundle Metalloproteins: One Scaffold, Diverse Reactivities. Acc. Chem. Res. 52 (5), 1148-1159. doi:10.1021/acs.accounts. $8 \mathrm{~b} 00674$

Lyons, T. W., and Sanford, M. S. (2010). Palladium-Catalyzed Ligand-Directed C-H Functionalization Reactions. Chem. Rev. 110 (2), 1147-1169. doi:10.1021/ cr900184e

Macchioni, A. (2019). The Middle-Earth between Homogeneous and Heterogeneous Catalysis in Water Oxidation with Iridium. Eur. J. Inorg. Chem. 2019 (1), 7-17. doi:10.1002/ejic.201800798

Maeda, K., Uemura, Y., Chun, W.-J., Satter, S. S., Nakajima, K., Manaka, Y., et al. (2020). Controllable Factors of Supported Ir Complex Catalysis for Aromatic C-H Borylation. ACS Catal. 10 (24), 14552-14559. doi:10.1021/acscatal. 0c03734

McNamara, C. A., Dixon, M. J., and Bradley, M. (2002). Recoverable Catalysts and Reagents Using Recyclable Polystyrene-Based Supports. Chem. Rev. 102 (10), 3275-3300. doi:10.1021/cr0103571

McNamara, N. D., and Hicks, J. C. (2014). CO2Capture and Conversion with a Multifunctional Polyethyleneimine-Tethered Iminophosphine Iridium Catalyst/Adsorbent. ChemSusChem 7 (4), 1114-1124. doi:10.1002/cssc. 201301231

Papa, V., Cao, Y., Spannenberg, A., Junge, K., and Beller, M. (2020). Development of a Practical Non-Noble Metal Catalyst for Hydrogenation of N-Heteroarenes. Nat. Catal. 3 (2), 135-142. doi:10.1038/s41929-019-0404-6

Rayner-Canham, G. (2011). Isodiagonality in the Periodic Table. Found. Chem. 13 (2), 121-129. doi:10.1007/s10698-011-9108-y

Bullock, R. M. (2010). in Catalysis without Precious Metals (Weinheim: Wiley VCH).

Roger, I., Shipman, M. A., and Symes, M. D. (2017). Earth-Abundant Catalysts for Electrochemical and Photoelectrochemical Water Splitting. Nat. Rev. Chem. 1 (1), 3. doi:10.1038/s41570-016-0003

Sahoo, B., Kreyenschulte, C., Agostini, G., Lund, H., Bachmann, S., Scalone, M., et al. (2018). A Robust Iron Catalyst for the Selective Hydrogenation of Substituted (Iso) Quinolones. Chem. Sci. 9 (42), 8134-8141. doi:10.1039/c8sc02744g

Schneiderman, D. K., and Hillmyer, M. A. (2017). 50th Anniversary Perspective: There Is a Great Future in Sustainable Polymers. Macromolecules 50 (10), 3733-3749. doi:10.1021/acs.macromol.7b00293

Schwarz, J. A., Contescu, C., and Contescu, A. (1995). Methods for Preparation of Catalytic Materials. Chem. Rev. 95 (3), 477-510. doi:10.1021/cr00035a002
Schwizer, F., Okamoto, Y., Heinisch, T., Gu, Y., Pellizzoni, M. M., Lebrun, V., et al (2018). Artificial Metalloenzymes: Reaction Scope and Optimization Strategies. Chem. Rev. 118 (1), 142-231. doi:10.1021/acs.chemrev.7b00014

Seechurn, J., Carin, C. C., Kitching, M. O., Colacot, T. J., and Snieckus, V. (2012). Palladium-Catalyzed Cross-Coupling: A Historical Contextual Perspective to the 2010 Nobel Prize. Angew. Chem. Int. Edition 51 (21), 5062-5085. doi:10. 1002/anie.201107017

Smieja, J. M., Sampson, M. D., Grice, K. A., Benson, E. E., Froehlich, J. D., Grice, K. A., et al. (2013). Manganese as a Substitute for Rhenium in CO2 Reduction Catalysts: The Importance of Acids. Inorg. Chem. 52 (5), 2484-2491. doi:10. 1021/ic302391u

Song, F., and $\mathrm{Hu}, \mathrm{X}$. (2014). Exfoliation of Layered Double Hydroxides for Enhanced Oxygen Evolution Catalysis. Nat. Commun. 5 (1), 4477. doi:10. 1038/ncomms5477

Stürzel, M., Mihan, S., and Mülhaupt, R. (2016). From Multisite Polymerization Catalysis to Sustainable Materials and All-Polyolefin Composites. Chem. Rev. 116 (3), 1398-1433. doi:10.1021/acs.chemrev.5b00310

Tasker, S. Z., Standley, E. A., and Jamison, T. F. (2014). Recent Advances in Homogeneous Nickel Catalysis. Nature 509 (7500), 299-309. doi:10.1038/nature13274

Wenger, O. S. (2019). Is Iron the New Ruthenium? Chem. Eur. J. 25 (24), 6043-6052. doi:10.1002/chem.201806148

Witzke, R. J., Chapovetsky, A., Conley, M. P., Kaphan, D. M., and Delferro, M. (2020). Nontraditional Catalyst Supports in Surface Organometallic Chemistry. ACS Catal. 10 (20), 11822-11840. doi:10.1021/acscatal.0c03350

Wolczanski, P. T. (2018). Activation of Carbon-Hydrogen Bonds via 1,2-RHAddition/-Elimination to Early Transition Metal Imides. Organometallics 37 (4), 505-516. doi:10.1021/acs.organomet.7b00753

Wu, F., Feng, Y., and Jones, C. W. (2014). Recyclable Silica-Supported Iridium Bipyridine Catalyst for Aromatic C-H Borylation. ACS Catal. 4 (5), 1365-1375. doi:10.1021/cs4009539

Yang, X., Sun, J.-K., Kitta, M., Pang, H., and Xu, Q. (2018). Encapsulating Highly Catalytically Active Metal Nanoclusters inside Porous Organic Cages. Nat. Catal. 1 (3), 214-220. doi:10.1038/s41929-018-0030-8

Yoon, M., Srirambalaji, R., and Kim, K. (2012). Homochiral Metal-Organic Frameworks for Asymmetric Heterogeneous Catalysis. Chem. Rev. 112 (2), 1196-1231. doi:10.1021/cr2003147

Zaccaria, F., Fagiolari, L., and Macchioni, A. (2020). Optimizing Noble Metals Exploitation in Water Oxidation Catalysis by Their Incorporation in Layered Double Hydroxides. Inorg. Chim. Acta 516, 120161. doi:10.1016/j.ica.2020. 120161

Zakzeski, J., Bruijnincx, P. C. A., Jongerius, A. L., and Weckhuysen, B. M. (2010). The Catalytic Valorization of Lignin for the Production of Renewable Chemicals. Chem. Rev. 110 (6), 3552-3599. doi:10.1021/cr900354u

Zell, T., and Langer, R. (2018). From Ruthenium to Iron and Manganese-A Mechanistic View on Challenges and Design Principles of Base-Metal Hydrogenation Catalysts. ChemCatChem 10 (9), 1930-1940. doi:10.1002/cctc.201701722

Zhang, G., Scott, B. L., and Hanson, S. K. (2012). Mild and Homogeneous CobaltCatalyzed Hydrogenation of CC, CO, and CN Bonds. Angew. Chem. Int. Ed. 51 (48), 12102-12106. doi:10.1002/anie.201206051

Zhang, X., Huang, Z., Ferrandon, M., Yang, D., Robison, L., Li, P., et al. (2018). Catalytic Chemoselective Functionalization of Methane in a Metal-organic Framework. Nat. Catal. 1 (5), 356-362. doi:10.1038/s41929-018-0069-6

Conflict of Interest: The author declares that the research was conducted in the absence of any commercial or financial relationships that could be construed as a potential conflict of interest.

Copyright (C) 2021 Macchioni. This is an open-access article distributed under the terms of the Creative Commons Attribution License (CC BY). The use, distribution or reproduction in other forums is permitted, provided the original author(s) and the copyright owner(s) are credited and that the original publication in this journal is cited, in accordance with accepted academic practice. No use, distribution or reproduction is permitted which does not comply with these terms. 